\title{
Vertical specialization in an intercountry input-output framework
}

\author{
Erik Dietzenbacher
}

Received: 25 January 2010 / Accepted: 31 August 2010 / Published online: 17 September 2010

(C) The Author(s) 2010. This article is published with open access at Springerlink.com

\begin{abstract}
Vertical specialization occurs when countries specialize in certain stages of the global chain of production. Using national input-output tables, it has been proposed to measure vertical specialization as the import content of the exports. However, intercountry input-output tables precisely provide the detailed description of interdependencies of industries between countries that is of interest for global production chains. Therefore, it may be expected that vertical specialization is more adequately measured by using intercountry input-output tables than by using national input-output tables. This paper develops a method to measure vertical specialization for intercountry input-output tables and applies it to the case of six countries in the European Union in 1985 , for which data are readily available.
\end{abstract}

Keywords Vertical specialization · Trade linkages · Input-output analysis

JEL Classification R15 · F14 · C67

\section{Introduction}

Fragmentation was introduced by Jones and Kierzkowski (1990, 2005) to describe the organization of production processes. More and more, production processes are split into subsequent phases, which are carried out separately and in different countries. As a consequence, the trade of intermediate products becomes more important and vertical trading chains exhibit an increasing interconnectedness of industries across countries. Vertical specialization occurs when each country specializes in certain stages of the sequence of production. In an influential paper, Hummels et al. (2001) narrowed

E. Dietzenbacher $(\bowtie)$

Department of International Economics and Business, Faculty of Economics and Business,

University of Groningen, PO Box 800, 9700 AV Groningen, The Netherlands

e-mail: h.w.a.dietzenbacher@rug.nl 
the concept of vertical specialization by focusing on the imported inputs that are necessary for producing the exports. Vertical specialization for a country was measured by the export weighted average direct import coefficient or by the export weighted average import multiplier (including also the indirect import requirements). Essentially, what this measures is the import content of the exports. The empirical results were obtained from applying these measures to national input-output tables. ${ }^{1}$

The present paper extends the analysis by taking intercountry input-output tables as the starting-point. These tables are of the interregional type with countries acting as regions. Intercountry tables provide a detailed description of the interdependencies of industries between countries and thus reflect exactly what one is interested in. It may thus be expected that the results obtained from intercountry tables measure vertical specialization better than national tables do. The intuition for this stems from the fact that intercountry models include interregional feedback effects (affecting home production) and that the interregional spillovers incorporate indirect effects (affecting foreign production). ${ }^{2}$ Although the total amounts of imports and exports of a country do not change of course, what may change is the distribution of the total amount of imports of a country into how much can be imputed to exports and how much can be imputed to domestic deliveries.

To measure the import content of the exports, however, the standard formula does no longer suffice. The reason is that an important part of the exports is endogenous in the intercountry framework, whereas all exports are exogenous when using a national framework. I will adapt the method for measurement so as to cope with this endogeneity. The new measurement will be applied to the intercountry tables for six countries in the EU and the results will be compared to the results obtained from using the national tables only.

\section{The methodology}

The starting-point for the analysis is the intercountry input-output table as depicted in Fig. 1. Distinguish between country $R$, country $S$ (which in the empirical application is a group of countries), and the rest of the world $W$.

The $n \times n$ matrix $\mathbf{Z}^{R S}$ gives the intermediate deliveries from industry $i$ in country $R$ to industry $j$ in country $S$. The (column) vector $\mathbf{c}^{R}$ gives the domestic final demand

Fig. 1 The intercountry input-output table

\begin{tabular}{llllll}
\hline $\mathbf{Z}^{R R}$ & $\mathbf{Z}^{R S}$ & $\mathbf{c}^{R}$ & $\mathbf{e}^{R S}$ & $\mathbf{e}^{R W}$ & $\mathbf{x}^{R}$ \\
$\mathbf{Z}^{S R}$ & $\mathbf{Z}^{S S}$ & $\mathbf{c}^{S}$ & $\mathbf{e}^{S R}$ & $\mathbf{e}^{S W}$ & $\mathbf{x}^{S}$ \\
$\mathbf{M}^{W R}$ & $\mathbf{M}^{W S}$ & & & & \\
$\left(\mathbf{v}^{R}\right)^{\prime}$ & $\left(\mathbf{v}^{S}\right)^{\prime}$ & & & & \\
$\mathbf{x}^{R}$ & $\left(\mathbf{x}^{S}\right)^{\prime}$ & & & & \\
\hline
\end{tabular}

\footnotetext{
${ }^{1}$ It should be stressed that also other ways of quantifying vertical specialization and fragmentation in an input-output framework have been proposed (see, e.g., Sonis et al. 2000, 2002; Romero et al. 2009).

${ }^{2}$ The only other paper that uses an intercountry input-output model for measuring vertical specialization is - to my knowledge - Wang et al. (2009). Their approach, however, differs markedly from mine.
} 
in country $R$, consisting of private consumption, private investments and government expenditures. The vector $\mathrm{e}^{R S}$ gives exports of country $R$ to country $S$, for domestic final demand purposes in country $S$. The vector $\mathbf{e}^{R W}$ gives the exports of country $R$ to the rest of the world $(W)$, for both final demand purposes and intermediate use in the production processes. The vector $\mathbf{x}^{R}$ gives the gross outputs in country $R$. The matrix $\mathbf{M}^{W R}$ gives the imports from industry $i$ located in the rest of the world into industry $j$ in country $R$. The (row) vector $\left(\mathbf{v}^{R}\right)^{\prime}$ gives the value added in country $R$.

The coefficients matrices are determined as follows. $\mathbf{A}^{R R}=\mathbf{Z}^{R R}\left(\hat{\mathbf{x}}^{R}\right)^{-1}$, where a "hat" is used to indicate a diagonal matrix. Similarly, $\mathbf{A}^{R S}=\mathbf{Z}^{R S}\left(\hat{\mathbf{x}}^{S}\right)^{-1}, \mathbf{A}^{S R}=$ $\mathbf{Z}^{S R}\left(\hat{\mathbf{x}}^{R}\right)^{-1}$ and $\mathbf{A}^{S S}=\mathbf{Z}^{S S}\left(\hat{\mathbf{x}}^{S}\right)^{-1}$. Let the row vector with the column sums of the import matrices be given by $\left(\mathbf{m}^{W R}\right)^{\prime}=\sigma^{\prime} \mathbf{M}^{W R}$ and $\left(\mathbf{m}^{W S}\right)^{\prime}=\sigma^{\prime} \mathbf{M}^{W S}$, where $\boldsymbol{\sigma}$ indicates the column summation vector consisting entirely of ones. Their $j$ th element gives the total imports into industry $j$ in countries $R$ and $S$, respectively. The row vectors with import coefficients are given by $\left(\mathbf{b}^{W R}\right)^{\prime}=\left(\mathbf{m}^{W R}\right)^{\prime}\left(\hat{\mathbf{x}}^{R}\right)^{-1}$ and $\left(\mathbf{b}^{W S}\right)^{\prime}=\left(\mathbf{m}^{W S}\right)^{\prime}\left(\hat{\mathbf{x}}^{S}\right)^{-1}$. The $j$ th element of the first vector, for example, gives the total imports from the rest of the world into industry $j$ in country $R$, per unit of this industry's gross output. The input-output equations are now given by

$$
\left(\begin{array}{l}
\mathbf{x}^{R} \\
\mathbf{x}^{S}
\end{array}\right)=\left[\begin{array}{ll}
\mathbf{A}^{R R} & \mathbf{A}^{R S} \\
\mathbf{A}^{S R} & \mathbf{A}^{S S}
\end{array}\right]\left(\begin{array}{l}
\mathbf{x}^{R} \\
\mathbf{x}^{S}
\end{array}\right)+\left(\begin{array}{l}
\mathbf{c}^{R}+\mathbf{e}^{R S}+\mathbf{e}^{R W} \\
\mathbf{c}^{S}+\mathbf{e}^{S R}+\mathbf{e}^{S W}
\end{array}\right)
$$

which can be rewritten as

$$
\left(\begin{array}{c}
\mathbf{x}^{R} \\
\mathbf{x}^{S}
\end{array}\right)=\left[\begin{array}{ll}
\mathbf{L}^{R R} & \mathbf{L}^{R S} \\
\mathbf{L}^{S R} & \mathbf{L}^{S S}
\end{array}\right]\left(\begin{array}{c}
\mathbf{c}^{R}+\mathbf{e}^{R S}+\mathbf{e}^{R W} \\
\mathbf{c}^{S}+\mathbf{e}^{S R}+\mathbf{e}^{S W}
\end{array}\right)
$$

where

$$
\left[\begin{array}{ll}
\mathbf{L}^{R R} & \mathbf{L}^{R S} \\
\mathbf{L}^{S R} & \mathbf{L}^{S S}
\end{array}\right]=\left[\begin{array}{cc}
\mathbf{I}-\mathbf{A}^{R R} & -\mathbf{A}^{R S} \\
-\mathbf{A}^{S R} & \mathbf{I}-\mathbf{A}^{S S}
\end{array}\right]^{-1}
$$

In determining the import content of the exports of country $R$, it is important to note that some of the exports are exogenously given (i.e. $\mathrm{e}^{R S}$ and $\mathbf{e}^{R W}$ ), while another part is determined endogenously. These are the exports from country $R$ that are embodied (i.e. used directly and indirectly) in the final demands in country $S$.

Consider first the import content of the exports $\mathbf{e}^{R S}$ and $\mathbf{e}^{R W}$. Element $(i, j)$ of the matrix $\mathbf{L}^{R R}\left(\hat{\mathbf{e}}^{R S}+\hat{\mathbf{e}}^{R W}\right)$ gives the production in industry $i$ in country $R$, that is embodied in the exports of good $j$ to country $S$ for its domestic final demands and to the rest of the world. The $j$ th element of the row vector $\left(\mathbf{b}^{W R}\right)^{\prime} \mathbf{L}^{R R}\left(\hat{\mathbf{e}}^{R S}+\hat{\mathbf{e}}^{R W}\right)$ gives the total imports from the rest of the world that are required for the exports of good $j$ to final demand in country $S$ and to the rest of the world. In the same way, element $(i, j)$ of the matrix $\mathbf{L}^{S R}\left(\hat{\mathbf{e}}^{R S}+\hat{\mathbf{e}}^{R W}\right)$ gives the production in industry $i$ in country $S$, that is required for (and embodied in) the same exports of good $j$. These 
Table 1 Summary of export and import vectors

\begin{tabular}{|c|c|c|}
\hline \multicolumn{3}{|l|}{ Exports } \\
\hline Element $j$ of: & & \\
\hline Column vector & $\mathbf{e}^{R S}+\mathbf{e}^{R W}$ & $\exp ^{1}$ \\
\hline Column vector & $\mathbf{L}^{R S}\left(\mathbf{c}^{S}+\mathbf{e}^{S R}+\mathbf{e}^{S W}\right)$ & $\exp ^{2}$ \\
\hline \multicolumn{3}{|l|}{ Imports } \\
\hline Element $j$ of: & & \\
\hline Row vector & $\left(\mathbf{b}^{W R}\right)^{\prime} \mathbf{L}^{R R}\left(\hat{\mathbf{e}}^{R S}+\hat{\mathbf{e}}^{R W}\right)$ & $\left(\mathbf{i m p}^{1}\right)$ \\
\hline Row vector & $\boldsymbol{\sigma}^{\prime} \mathbf{L}^{S R}\left(\hat{\mathbf{e}}^{R S}+\hat{\mathbf{e}}^{R W}\right)$ & $\left(\mathbf{i m p}^{2}\right)$ \\
\hline Column vector & $\left(\hat{\mathbf{b}}^{W R}\right) \mathbf{L}^{R S}\left(\mathbf{c}^{S}+\mathbf{e}^{S R}+\mathbf{e}^{S W}\right)$ & imp $^{3}$ \\
\hline
\end{tabular}

are imports from country $S$ to country $R$. The total imports required for the exports of good $j$ to final demand in country $S$ and to the rest of the world are given by the $j$ th element of the row vector $\left[\left(\mathbf{b}^{W R}\right)^{\prime} \mathbf{L}^{R R}+\boldsymbol{\sigma}^{\prime} \mathbf{L}^{S R}\right]\left(\hat{\mathbf{e}}^{R S}+\hat{\mathbf{e}}^{R W}\right)$.

Next, the import content of the endogenous exports will be determined. These exports are determined by the demand in country $S$ for inputs from country $R$. Embodied in the final demands $\mathbf{c}^{S}+\mathbf{e}^{S R}+\mathbf{e}^{S W}$ of country $S$ are goods and services produced in country $R$ to the amount $\mathbf{L}^{R S}\left(\mathbf{c}^{S}+\mathbf{e}^{S R}+\mathbf{e}^{S W}\right)$. The $j$ th element of this column vector thus gives the endogenously determined exports of good $j$ from country $R$ to country $S$. The imports from the rest of the world that are involved in these endogenous exports amount to the $j$ th element of the column vector $\left(\hat{\mathbf{b}}^{W R}\right) \mathbf{L}^{R S}\left(\mathbf{c}^{S}+\mathbf{e}^{S R}+\mathbf{e}^{S W}\right)$.

A summary of import contents corresponding to the exports of product $j$ from country $R$ is given in Table 1 . The measure of vertical specialization is-for each product $j$-obtained as

$$
\frac{\operatorname{imp}_{j}^{1}+\mathbf{i m p}_{j}^{2}+\mathbf{i m p}_{j}^{3}}{\exp _{j}^{1}+\exp _{j}^{2}}
$$

and the overall measure at the national level is given by

$$
\frac{\sigma^{\prime}\left(i m p^{1}+i m p^{2}+i m p^{3}\right)}{\sigma^{\prime}\left(\exp ^{1}+\exp ^{2}\right)}
$$

If only the national input-output table is available, the exports for country $R$ are exogenously given by the vector $\exp =\mathbf{z}^{R S}+\mathbf{e}^{R S}+\mathbf{e}^{R W}$, where $\mathbf{z}^{R S}=\mathbf{Z}^{R S} \boldsymbol{\sigma}$. The production of industry $i$ in country $R$ that is necessary to satisfy the export of product $j$ is given by the element $(i, j)$ of the matrix $\left(\mathbf{I}-\mathbf{A}^{R R}\right)^{-1}\left(\hat{\mathbf{z}}^{R S}+\hat{\mathbf{e}}^{R S}+\hat{\mathbf{e}}^{R W}\right)$. The total amount of imports necessary for the export of product $j$ are given by the $j$ th element of the row vector $\mathbf{i m p} \mathbf{p}^{\prime}=\left[\boldsymbol{\sigma}^{\prime} \mathbf{A}^{S R}+\left(\mathbf{b}^{W R}\right)^{\prime}\right]\left(\mathbf{I}-\mathbf{A}^{R R}\right)^{-1}\left(\hat{\mathbf{z}}^{R S}+\hat{\mathbf{e}}^{R S}+\hat{\mathbf{e}}^{R W}\right)$. In the single country case, the expressions (4) and (5) are replaced by the original Hummels et al. (2001) measures. That is,

$$
\frac{\operatorname{imp}_{j}}{\exp _{j}} \text { and } \frac{\sigma^{\prime} \text { imp }}{\sigma^{\prime} \exp }
$$




\section{An application to the 1985 intercountry input-output table for six European countries}

In order to empirically illustrate the differences that may appear between the two approaches, I have used the intercountry input-output table for 1985, with six European countries (also indicated as 6-EU). ${ }^{3}$ These are: Germany (G), France (F), Italy (I), the Netherlands (N), Belgium (B), and Denmark (D). The table is a full interregional type of table and covers 25 industries. The table was constructed from combining the harmonized national input-output tables (see Eurostat 1979) of the six countries. The details of the construction method are given in van der Linden (1999), a summary is given by van der Linden and Oosterhaven (1995). The results are given in Table 2, where columns (a) show the results obtained by using the intercountry input-output table (i.e. following the formulae in Table 1), and columns (b) show the findings if only the national input-output tables are used.

\subsection{Results at the national level}

The outcomes for vertical specialization at the national level are given in the bottom row of Table 2. The most important finding is that the differences between the two approaches (i.e. using a full intercountry table or just the national tables) are relatively small. For most countries the difference is less than $10 \%$. From a practical point of view, the finding that the results are fairly robust contains a relevant message. Although one may argue that using intercountry tables is to be preferred on theoretical grounds (because they exactly incorporate the trade relations that one would like to measure), such tables are usually not readily available and need to be constructed (which is a painstaking and time-consuming process). In contrast, national inputoutput tables are now widely available and do not require much additional work if one aims at a comparison of national vertical specialization across countries. ${ }^{4}$ If the results of one method are a good approximation for the results of a superior but cumbersome method, the choice seems easily made.

Second, observe that the differences between the two approaches can be positive as well as negative. On the one hand, this suggests that there is no systematic bias (in the sense of the difference being always positive or always negative). On the other hand, because there is no systematic bias, the ordering of countries according

\footnotetext{
${ }^{3}$ Unfortunately, intercountry input-output tables are rare. An exception is the series of tables, constructed by researchers from the University of Groningen, for a set of European countries. For the present application I have used the most recent year that is available. The full series of intercountry tables in current prices (for the years 1965, 1970, 1975, 1980, and 1985) can be downloaded at http://www.regroningen.nl. For the intercountry tables in constant prices, see Hoen (2002). The importance of intercountry tables, however, has been widely recognized. For example, the EU-funded project WIOD aims at constructing a series of annual inter-country input-output tables (in current and constant prices) for 40 countries in the world (see http://www.wiod.org). It should be stressed that at this moment also other intercountry tables are being developed (see e.g. Tukker et al. 2009, reporting on the EXIOPOL project) or have been constructed (see e.g. Oosterhaven et al. 2008). None of these datasets, however, is publicly available.

${ }^{4} \mathrm{As}$ long as one is interested in the results at the national level, it is even not necessary to make the industry classification uniform. For example, one might use a 97 industry classification for country A and compare its vertical specialization with that of country B as based on a 38 industry classification.
} 


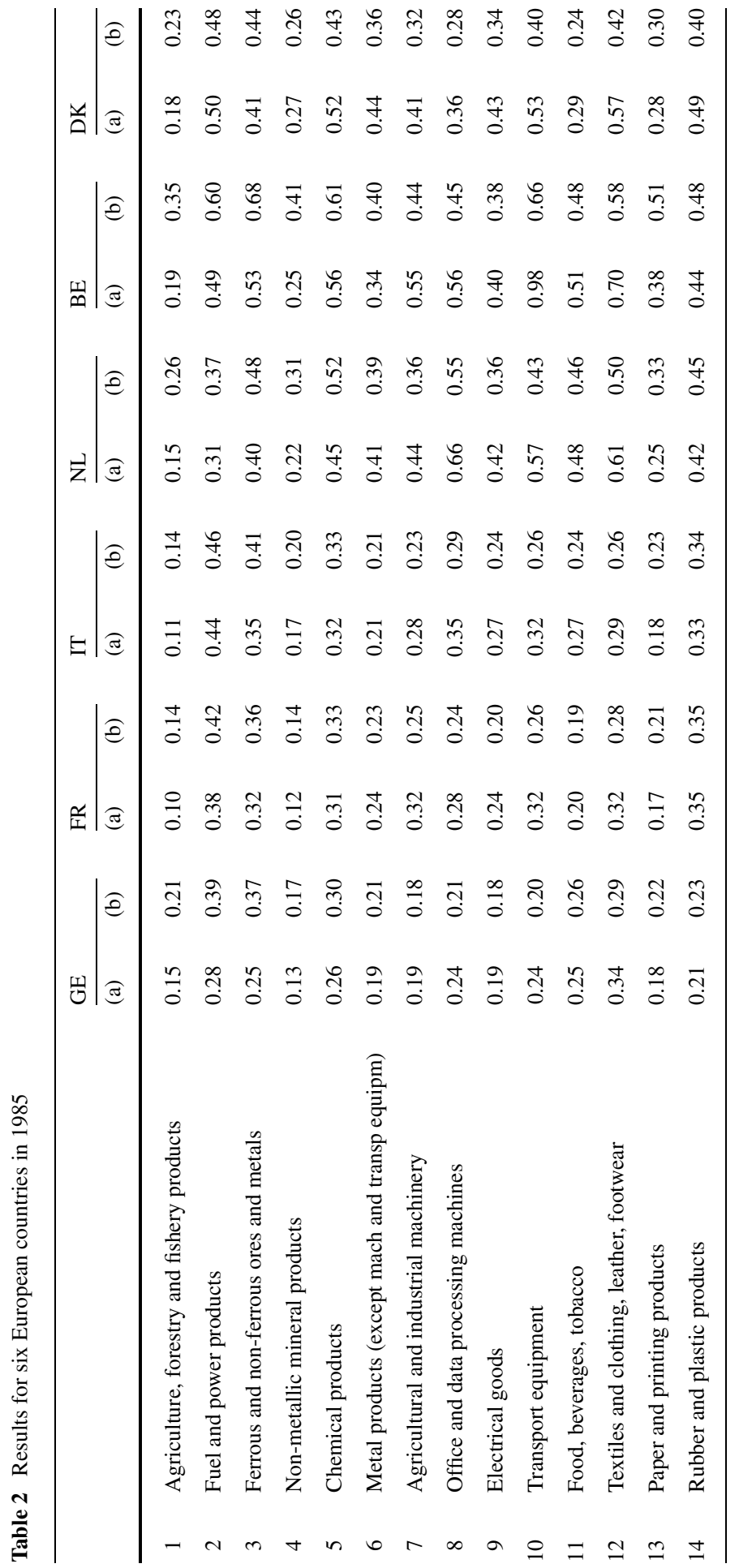




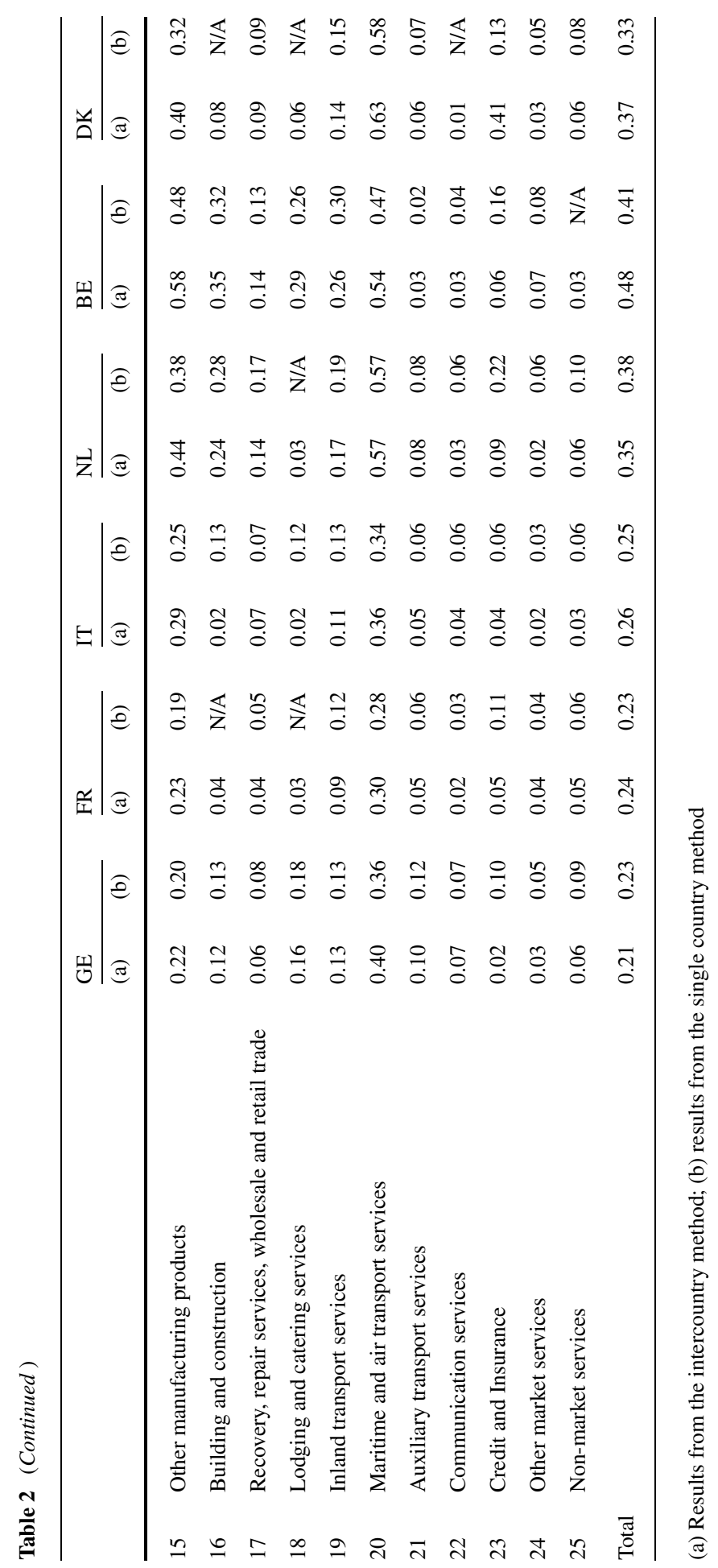


to size of vertical specialization might differ across methods. For example, if the national input-output tables are used, Belgium and the Netherlands show by far the largest outcomes and their results are close to each other. If the intercountry table is used, the Belgian vertical specialization appears to be outstanding, followed by the Netherlands and Denmark at a considerable distance.

A third observation is that the results for the large countries (Germany, France, and Italy) are substantially smaller than the results for the small countries (the Netherlands, Belgium, and Denmark). This distinction has been reported earlier in several studies, applying different methods to the same dataset (see, e.g. Dietzenbacher et al. 1993, and Dietzenbacher and van der Linden 1997). Of course, this finding should not come as a surprise because smaller countries typically depend-for their production-more on imported inputs than larger countries (which are more selfsupporting) do. This holds for production in general and therefore also for exports (which result from the production process).

In order to get insight into the cause of the differences in the results, the differences in the methods of measurement will be elaborated first. When national tables are used, the import content of the actual exports are measured. When the intercountry table is used, the imports involved in the embodied exports are calculated. That is, the final demands in country $S$ (i.e. $\mathbf{c}^{S}+\mathbf{e}^{S R}+\mathbf{e}^{S W}$ ) are produced in country $S$, for which production is required in country $R$ to the amount of $\mathbf{L}^{R S}\left(\mathbf{c}^{S}+\mathbf{e}^{S R}+\mathbf{e}^{S W}\right)$. These are the exports embodied in $\mathbf{c}^{S}+\mathbf{e}^{S R}+\mathbf{e}^{S W}$. At the industry level, observe that, for example, the vertical specialization of Building and construction (industry 16) in France could not be calculated. The reason is that France does not export products from this industry. However, the French building and construction industry does deliver products to other French industries (such as Fuel and power products, industry 2) that do export their products. The Belgian Chemical products sector (industry 5), for example, depends for its production on French fuel and power products and thus, indirectly, on the French building and construction industry. Hence, products from the French building and construction industry are embodied in the final demands for Belgian chemical products. In line with the definition of virtual water (see e.g. Dietzenbacher and Velázquez 2007), this would be the virtual export of French building and construction to Belgium. In a similar fashion, it may also happen that the embodied exports of a certain product are smaller than the actual exports.

The key difference between the two approaches is that using the intercountry table implies that the dependencies between the 6-EU countries are fully taken into account, also if they are indirect. When the national tables are used (plus the import matrices for trade with their partners in the 6-EU), only the direct trade linkages between countries are employed. This extra indirect interdependence may have two effects. On the one hand, it may happen that countries are more dependent on imports via other 6-EU countries in which case their vertical specialization will increase. This is the case, for France, Italy, Denmark, and in particular for Belgium whose linkages within the 6-EU are very interwoven. On the other hand, it may happen that a country's products become more embodied in the final demands of its 6-EU trading partners. In that case, the embodied exports will increase and the vertical specialization will decline. This happens for Germany and the Netherlands. 


\subsection{Results at the industry level}

Whereas the results at the national level indicate a certain robustness, the differences between the two methods are much larger at the industry level. Observe also that the differences for the small countries are substantially larger than the differences for the large countries. Clearly, because the small countries depend more on imported inputs, taking the full direct and indirect linkages within the 6-EU into account affects small countries more than it does affect large countries.

The second observation is that the sign of the difference for a certain industry is the same for almost all countries. This finding holds for all industries, except for Metal products (industry 6). Observe that many of the service industries (16-25, except Maritime and air transport services, i.e. 20) show a lower vertical specialization in case the intercountry table is used than in case the national tables are used. These industries have a relatively strong "national" focus for their sales so that their actual exports will be limited. However, within the country many industries depend to some extent on inputs from the service industries. As a consequence, services exports will be more of an embodied nature, which will increase the denominator in the expression for vertical specialization. A similar reasoning applies to the other group of industries for which the vertical specialization in columns (a) is smaller than in columns (b). These are the industries 1-5, producing primary goods. Again, exports are embodied because various (in particular domestic) manufacturing industries depend on primary goods as inputs. In contrast, the input dependence of these primary industries is typically direct, implying that it makes little difference for the imports whether one method is used or the other. Most manufacturing industries $(7-12,15)$ exhibit a larger vertical specialization when the intercountry table is used than when the national tables are employed. Typically, these industries show a large dependence on other (in particular manufacturing) industries, often crossing the borders. In this case, the full direct and indirect linkages within the 6-EU countries are only taken into account if the intercountry table is used.

Acknowledgements Earlier versions of this paper have been presented at conferences in Seville (2008) and San Francisco (2009), I would like to thank Randall W. Jackson and participants, and two anonymous referees for their comments. I would like to thank Bing Zhao and Yan $\mathrm{Xu}$ for their help with the computations.

Open Access This article is distributed under the terms of the Creative Commons Attribution Noncommercial License which permits any noncommercial use, distribution, and reproduction in any medium, provided the original author(s) and source are credited.

\section{References}

Dietzenbacher, E., van der Linden, J.A.: Sectoral and spatial linkages in the EC production structure. J. Reg. Sci. 37, 235-257 (1997)

Dietzenbacher, E., Velázquez, E.: Analysing Andalusian virtual water trade in an input-output framework. Reg. Stud. 41, 185-196 (2007)

Dietzenbacher, E., van der Linden, J.A., Steenge, A.E.: The regional extraction method: EC input-output comparisons. Econ. Syst. Res. 5, 185-206 (1993)

Eurostat: European System of Integrated Economic Accounts-ESA, 2nd edn. Eurostat, Luxembourg (1979) 
Hoen, A.R.: An Input-Output Analysis of European Integration. North-Holland, Amsterdam (2002)

Hummels, D., Ishii, J., Yi, K.-M.: The nature and growth of vertical specialization in world trade. J. Int. Econ. 54, 75-96 (2001)

Jones, R.W., Kierzkowski, H.: The role of services in production and international trade: a theoretical framework. In: Jones, R.W., Krueger, A.O. (eds.) The Political Economy of International Trade: Essays in Honor of Robert E. Baldwin. Blackwell, Oxford (1990)

Jones, R.W., Kierzkowski, H.: International fragmentation and the new economic geography. N. Am. J. Econ. Finance 16, 1-10 (2005)

Oosterhaven, J., Stelder, D., Inomata, S.: Estimating international interindustry linkages: non-survey simulations of the Asian-Pacific economy. Econ. Syst. Res. 20, 395-414 (2008)

Romero, I., Dietzenbacher, E., Hewings, G.J.D.: Fragmentation and complexity: analyzing structural change in the Chicago regional economy. Rev. Econ. Mund. 23, 263-282 (2009)

Sonis, M., Hewings, G.J.D., Okuyama, Y.: Vertical specialization and interregional trade: turbulence analogy and feedback loops analysis of the Midwest economy. In: Herrmann, H., Bröcker, J. (eds.) Spatial Change and Interregional Flows in the Integrating Europe. Physica, Heidelberg (2000)

Sonis, M., Hewings, G.J.D., Okuyama, Y.: Vertical specialization and spatial production cycles in interregional trade: feedback loops analysis of the Midwest economy. In: Hewings, G.J.D., Sonis, M., Boyce, D. (eds.) Trade, Networks and Hierarchies. Springer, Heidelberg (2002)

Tukker, A., Poliakov, E., Heijungs, R., Hawkins, T., Neuwahl, F., Rueda-Cantuche, J.M., Giljum, S., Moll, S., Oosterhaven, J., Bouwmeester, M.: Towards a global multi-regional environmentally extended input-output database. Ecol. Econ. 69, 1928-1937 (2009)

van der Linden, J.A.: Interdependence and Specialisation in the European Union. PhD Thesis, University of Groningen, Faculty of Economics, The Netherlands (1999)

van der Linden, J.A., Oosterhaven, J.: European Community intercountry input-output relations: construction method and main results for 1965-1985. Econ. Syst. Res. 7, 249-269 (1995)

Wang, Z., Powers, W., Wei, S.-J.: Value chains in East Asian production networks-an international inputoutput model based analysis. Office of Economics Working Paper 2009-10-C, U.S. International Trade Commission (2009) 